made in groups with differing severities of illness or temperatures intergroup comparisons of the means of the logarithmic values were made by Student's unpaired $t$ test. Case 4 was excluded from statistical analyses involving gastrin concentrations.

\section{Discussion}

Stress ulceration of the gastrointestinal tract may result from thermal burns, ${ }^{5}$ but its aetiology is obscure. Gastric acid secretion is raised in the burned patient, ${ }^{6}$ and gastrin secretion, which stimulates gastric acid production, is promoted by sympathetic adrenergic activity, which occurs in acutely stressful circumstances. Possibly stress ulcers occur as a result of excessive acid secretion provoked by hypergastrinaemia. The delay before the occurrence of these ulcers, which may present days or weeks after the initial insult, ${ }^{7}$ might be invoked by damage to the gastric mucosa, caused by ischaemia or other insults, which needs time to recover before gastric secretory function returns.

Though gastric secretion is abnormally high in burned patients the increase is less obvious in patients with the largest burns. ${ }^{6}$ In an earlier study ${ }^{8}$ only four patients out of 20 with Curling's ulcer showed evidence of acid hypersecretion, but unless serial samples are measured throughout the burn illness one cannot know whether these acid levels remain within the normal range. Another report ${ }^{9}$ recorded raised serum gastrin levels in one out of three burned patients with gastrointestinal haemorrhage, but again sampling was infrequent and could have missed the important rise observed in our patient with a Curling ulcer (Case 5). Our only patient to develop hypergastrinaemia after the immediate post-burn period was also the only patient who developed an acute gastrointestinal haemorrhage as the result of acute stress ulceration. This strongly suggests that hypersecretion of gastrin may play a part in the pathogenesis of acute stress ulcers. If this relation could be established it would be of practical value because stress ulceration carries a high mortality and prophylactic measures might be feasible.

The increase in plasma glucagon levels has already been described in burned patients ${ }^{10}$ and some of the metabolic implications discussed. We also observed raised glucagon levels in patients with major burns and, though they correlated with the percentage of surface area affected, gross increases in glucagon levels occurred when systemic complications supervened. Thus the severity of the illness seems to be a more potent stimulator of glucagon production than the burn injury itself.

Plasma glucagon concentrations are high in starvation, ${ }^{11}$ diabetes, ${ }^{12}$ severe infection, ${ }^{13}$ trauma, ${ }^{14}$ and burns. ${ }^{10}$ Under these conditions glucose is manufactured from products of protein degradation by gluconeogenesis and ketosis, and under some circumstances an accompanying acidosis results from the excessive mobilization and catabolism of fatty acids.

Glucagon is one of the most potent agents activating and inducing the enzymes of gluconeogenesis, ${ }^{15}$ and in man the infusion of this hormone results in a considerable increase in protein catabolism and urinary urea excretion. ${ }^{16}$ The close correlation between plasma concentrations of glucagon and those of urea and glucose and the inverse correlation with bicarbonate support suggestions that glucagon plays a causal part in the hypercatabolic state.

The recent discovery that growth hormone-release inhibiting hormone blocks glucagon release in man without any significant side effects ${ }^{17}$ raises the possibility that this compound may be of clinical value in limiting the metabolic derangements of hypercatabolic states induced by hyperglucagonaemia.

We thank Mr. A. J. Evans and Mr. P. J. Whitfield for their encouragement in pursuing this study in their patients. A.W.S. was supported by the Medical Research Council, and S.R.B., who is an M.R.C. clinical research fellow, also receives support from the British Diabetic Association.

\section{References}

${ }^{1}$ Evans, A. J., British fournal of Plastic Surgery, 1953, 5, 263.

2 Bloom, S. R., British Medical Bulletin, 1974, 30, 62.

3 Bloom, S. R., Gut, 1974, 15, 502.

4 Walsh, J. H., Debas, H. T., and Grossman, M. I., fournal of Clinical Investigation, 1974, 54, 477 .

${ }^{5}$ Curling, T. B., Medico-chirurgical Transactions, 1842, 25, 260.

5 Curling, T. B., Medico-chirurgical Transactions, 1842, 25, 260.
${ }^{6}$ Harrison, A. M., Gaisford, J. E., and Wechsler, R. I., fournal of Trauma, 1972, 12, 1041.

7 Shepherd, J. A., Surgery of the Acute Abdomen, 2nd ed. Livingston, London, 1968.

${ }^{8}$ O'Neill, J. A., Surgery, 1970, 67, 267.

${ }^{9}$ Newsome, T.' W., et al., Archives of Surgery, 1973, 107, 622.

10 Wilmore, D. W., et al., Lancet, 1974, 1,73.

11 Aguila-Parada, E., Eisentraut, A. M., and Unger, R. H., Diabetes, 1969, 18, 717 .

12 Unger, R. H., Madison, L. L., and Müller, W. A., Diabetes, 1972, 21, 301.

13 Rocha, D. M., et al., New England fournal of Medicine, 1973, 288, 700.

14 Meguid, M. M., et al., Surgical Forum, 1973, 24, 97.

15 Exton, J. H., et al., Recent Progress in Hormone Research, 1970, 26, 411.

16 Marliss, E B., et al., Journal of Clinical Investigation, 1970, 49, 2256.

17 Mortimer, C. H., et al., Lancet, 1974, 1, 697.

\title{
Successful Pregnancy in Patient on Regular Dialysis
}

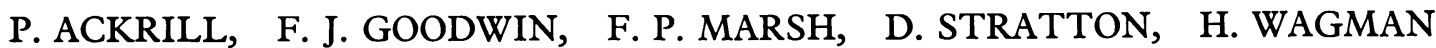

\section{Introduction}

Chronic renal failure in women is associated with irregular or absent menstruation, ${ }^{1}$ impaired fertility, ${ }^{2}$ and, if conception is achieved, a high incidence of complications and fetal wastage..$^{3-4}$ Patients on regular dialysis treatment (R.D.T.) may, however, resume normal menstruation, ovulate, ${ }^{5}$ and become pregnant, ${ }^{6}$ though most pregnancies if they do not abort spontaneously are terminated. ${ }^{6}$ Only two successful pregnancies have been reported $^{6}{ }^{7}$; we report here a third.

\section{Case Report} P. ACKRILL, M.B., M.R.C.P., Senior Registrar, Department of Nephrology.
(Present appointment: Senior Registrar, St. Bartholomew's Hospital, London E.C.1).

F. J. GOODWIN, M.B., M.R.C.P., Consultant Nephrologist

F. P. MARSH, M.B., M.R.C.P., Consultant Nephrologist

D. STRATTON, M.B., M.R.C.P., Lecturer in Paediatrics WAGMAN, F.R.C.S., M.R.C.O.G., Senior Registrar, Department of
Obstetrics and Gynaecology. (Present appointment: Consultant ObstetObstetrics and Gynaecology. (Present appc
rician, Barnet General Hospital, Herts.)
A 24-year-old nulliparous married woman developed hypertension and renal failure due to bilateral renal scarring with vesicoureteric creatinine clearance was $2.2 \mathrm{ml} / \mathrm{min}$ with a $1.0 \mathrm{~m}^{2}$ standard Kiil dialyser for 10 hours thrice weekly. Hypertension was controlled by ultrafiltration, and dialysis was later reduced to eight hours thrice reflux and recurrent bacteriuria. She began R.D.T. when her 
weekly. Predialysis plasma urea and creatinine concentrations varied from 7.5 to $9.1 \mathrm{mmol} / \mathrm{l}(45-55 \mathrm{mg} / 100 \mathrm{ml})$ and from 460 to $513 \mu \mathrm{mol} / 1$ $(5.2$ to $5.8 \mathrm{mg} / 100 \mathrm{ml})$ respectively. Her haemoglobin concentration rose from 5.5 to $8.6 \mathrm{~g} / \mathrm{dl}$ during treatment with intravenous iron.

She had taken an oral contraceptive for three years before starting R.D.T. but in view of her advanced renal failure contraception was discontinued. Menstruation was initially regular but 20 months after the start of R.D.T. she presented with amenorrhoea and was found clinically to be about 16 weeks pregnant. Three weeks later ultrasonic cephalometry staged the pregnancy at 17 weeks. She wanted to continue the pregnancy and accordingly dialysis was planned with three major objectives: (a) maintenance of blood urea at less than $16.6 \mathrm{mmol} / \mathrm{l}(100 \mathrm{mg} / 100 \mathrm{ml})$ while ensuring adequate nutrition, $(b)$ rigid control of blood pressure, and (c) minimal fluctuation in fluid balance.

Dietary control had always been difficult so she was allowed a relatively free intake and dialysed more often; from the 14th week she was dialysed for 30 hours a week, and from the 19 th week, when her blood urea had risen to $15.4 \mathrm{mmol} / 1(93 \mathrm{mg} / 100 \mathrm{ml})$, she was dialysed five times a week for a total of 37 hours using a combination of home dialysis (standard Kiil dialyser) and hospital dialysis $\left(1.0 \mathrm{~m}^{2}\right.$ Meltec Multipoint dialyser). Potassium supplements were not required. Predialysis plasma urea and creatinine and haemoglobin concentrations are shown in fig. 1. Estimations were kept to a minimum in an attempt to avoid blood transfusion.

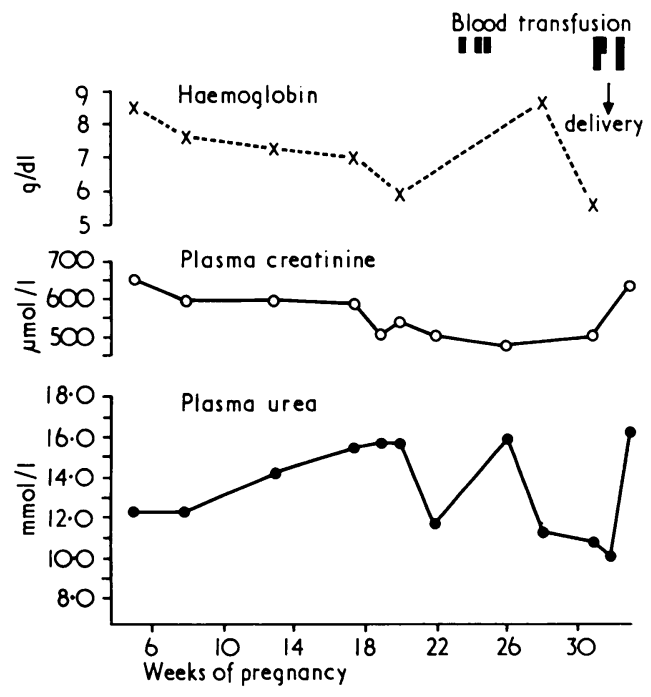

FIG. I-Changes in predialysis haemoglobin, plasma urea, and creatinine concentrations during pregnancy. Conversion: SI to Traditional Units-Creatinine: $1 \mu \mathrm{mol} / 1 \approx 0.0113 \mathrm{mg} / 100 \mathrm{ml} .1 \mathrm{mmol} / \mathrm{l} \approx 6 \mathrm{mg} / 100 \mathrm{ml}$.

During most of her pregnancy daily dietary intake contained at least $70 \mathrm{~g}$ protein, $55 \mathrm{mmol}$ potassium, $80 \mathrm{mmol}$ sodium, $1500 \mathrm{mg}$ calcium, 200 IU vitamin D, and $10 \mathrm{MJ}$ (2400 kcal). She was given oral supplements of dialysable vitamins (Albee with vitamin $\mathrm{C}$ tablets 2 /day) folic acid and iron (Slow-Fe Folic tablets 2/day), but no calcium or vitamin $\mathrm{D}$ supplements (dialysate calcium concentration $1.63 \mathrm{mmol} / 1(3.25 \mathrm{mEq} / 1)$. Increasing anaemia necessitated blood transfusion at 24 weeks; $200 \mathrm{ml}$ of nitrogen-frozen red cells was given during each of three separate dialyses to minimize fluctuations in blood volume. Careful attention to fluid balance kept her interdialysis weight gain to under $0.5 \mathrm{~kg}$ until late pregnancy; control was aided by a dialy urinary output of about $800 \mathrm{ml}$ containing $40-50 \mathrm{mmol}$ sodium. Creatinine clearance measured on non-dialysis days was less than $1.5 \mathrm{ml} / \mathrm{min}$.

Fetal movements were first felt at 19 weeks. From the 20 th week considerable hydramnios obscured clinical assessment of fetal growth. Serial measurements of fetal biparietal diameter by ultrasonic cephalometry followed the normal curve throughout pregnancy, ${ }^{8}$ and this allowed accurate staging. Blood pressure was satisfactorily maintained at prepregnancy levels until about 28 weeks (fig. 2) but then became very labile, and she needed up to one litre of normal saline during dialysis to control symptomatic hypotension, while becoming progressively more hypertensive between dialyses.
During dialysis at an estimated 31 weeks she developed uterine contractions which diminished after oral salbutamol. Five days later when further contractions occurred she developed basal crepitations and an increased jugular venous pressure, required urgent dialysis and was transfused with two units of nitrogen-frozen red cells as her haemoglobin concentration had fallen to $5.5 \mathrm{~g} / \mathrm{dl}$. After dialysis, despite losing two $\mathrm{kg}$, she became severely hypertensive (240/150 $\mathrm{mm} \mathrm{Hg}$ ). There was no response to pethidine and promazine sedation but blood pressure was reduced to $140 / 80 \mathrm{~mm} \mathrm{Hg}$ by a 24 -hour continuous intravenous infusion of hydrallazine. The next day a further dialysis and blood transfusion was uneventful. Labour began during the next dialysis and a 1530-g male infant was delivered by assisted breech delivery after a first stage lasting seven hours and a second stage lasting 24 minutes. The first stage was complicated by a small intrapartum haemorrhage and the estimated total blood loss was $750 \mathrm{ml}$. The placenta weighed $600 \mathrm{~g}$ and was pale, infarcted, and thought to be praevia. Postdelivery blood pressure was $120 / 90 \mathrm{~mm}$ $\mathrm{Hg}$. A moderate postpartum haemorrhage occurred at the onset of dialysis two days after delivery, which required transfusion, but thereafter the puerperium was uneventful. One week after delivery her blood pressure was $130 / 70 \mathrm{~mm} \mathrm{Hg}$ and her weight had almost returned to that before pregnancy (fig. 2).

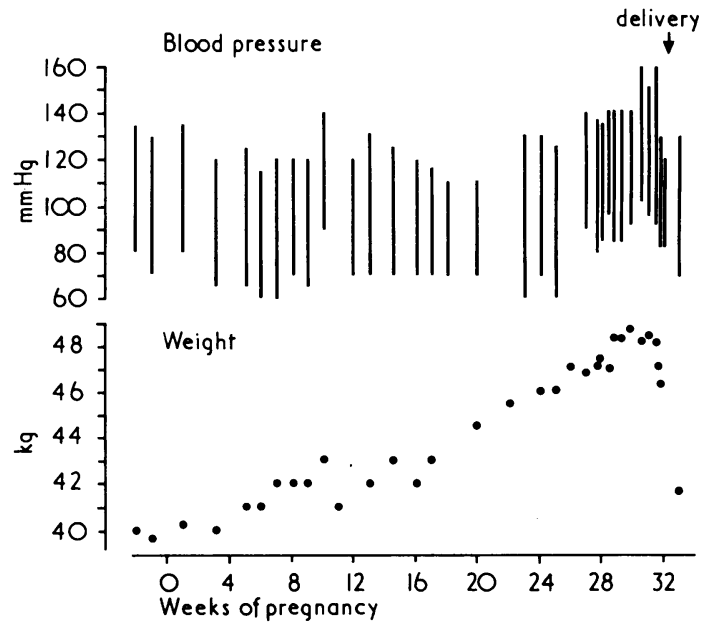

FIG. 2-Serial measurements of predialysis weight and blood pressure during pregnancy.

The infant had an Apgar score of 3 at one minute and required resuscitation with intermittent positive pressure ventilation. He was extubated at seven minutes and admitted to the neonatal intensive care unit. Signs of respiratory distress appeared at 30 minutes but responded to added oxygen. The infant's blood urea was $10 \cdot 8 \mathrm{mmol} / \mathrm{l}$ $(65 \mathrm{mg} / 100 \mathrm{ml}$ ) and plasma potassium $2.4 \mathrm{mmol} / 1$ compared with maternal figures of $9.8 \mathrm{mmol} / 1(60 \mathrm{mg} / 100 \mathrm{ml})$ and $2 \cdot 1 \mathrm{mmol} / 1$ respectively. The plasma electrolyte concentrations became normal at 12 hours, after intravenous dextrose and potassium supplements. Hyperbilirubinaemia reached its maximum on the fourth day (unconjugated bilirubin $311 \mu \mathrm{mol} / 1(18.2 \mathrm{mg} / 100 \mathrm{ml}$ ) and responded to conservative management. Gestational maturity was assessed at 32 weeks. $^{9}$ There was no evidence of any congenital abnormality.

The infant's fluid balance and nutrition were maintained via the umbilical artery and progress was satisfactory until the fifth day when recurring cyanotic attacks required intubation and assisted ventilation. Infection was considered the most likely cause though cultures proved sterile. He was treated with parenteral gentamicin and cephalothin and improved after a stormy course and was finally extubated on the 15th day. He was discharged home at seven weeks weighing $23700 \mathrm{~g}$. Follow-up over his first year showed no physical abnormality and development was compatible with chronological age as assessed on the Denver developmental scale. ${ }^{10}$

\section{Discussion}

Haemodialysis has been used for limited periods to prolong pregnancy and thereby permit fetal survival in severe preeclamptic toxaemia, ${ }^{11}$ acute nephritis due to systemic lupus, ${ }^{12}$ 
and chronic renal disease not itself necessitating dialysis. ${ }^{13} 14$ But there are only two reports of successful pregnancy in patients who conceived during R.D.T., ${ }^{78}$ and one other in which a live infant survived for only 12 hours. ${ }^{15}$ One of the patients with a successful pregnancy ${ }^{7}$ started R.D.T. with a creatinine clearance of $9.2 \mathrm{ml} / \mathrm{min}$ and during the pregnancy three years later needed no increase in her routine 12 hours' dialysis twice weekly. Measurements of creatinine clearance during pregnancy were not given and successful pregnancy might have been achieved without dialysis. ${ }^{7}$ In the other patient ${ }^{8}$ creatinine clearance varied from 4.0 to $6.5 \mathrm{ml} / \mathrm{min}$ and the dialysis was increased to eight hours three to four times weekly to keep the blood urea below $12.5 \mathrm{mmol} / 1(75 \mathrm{mg} / 100 \mathrm{ml})$. Our patient's creatinine clearance was less than $1.5 \mathrm{ml} / \mathrm{min}$, illustrating that conception and successful delivery of a viable infant can be achieved in patients with minimal residual renal function.

There is no evidence that maintenance of relatively low plasma urea and creatinine concentrations are essential for producing a viable infant, though we assumed that good dialysis is likely to improve the chances of a successful pregnancy. ${ }^{814}$

Tenney and Dandrow ${ }^{5}$ believed that intrauterine death was likely if the plasma urea concentration exceeded $21.6 \mathrm{mmol} / 1$ (130 mg/100 $\mathrm{ml}$ ) for more than one week. But success has been achieved despite plasma urea concentrations above $33.2 \mathrm{mmol} / 1\left(200 \mathrm{mg} / 100 \mathrm{ml}^{7} 12\right.$ and serum creatinine levels above $796 \mu \mathrm{mol} / 1(9.0 \mathrm{mg} / 100 \mathrm{ml})$. Frequent dialysis certainly rendered dietary management and control of weight gain much easier, but the domestic problems caused were solved only by a combination of home and hospital dialysis.

Maternal nutrition during the pregnancy was satisfactorily maintained. Serum albumin concentration fell normally ${ }^{16}$ from 46 to $36 \mathrm{~g} / \mathrm{l}$. Though her vitamin $\mathrm{D}$ intake was less than that recommended for pregnant patients with normal renal function ${ }^{17}$ serum alkaline phosphatase remained normal, and skeletal surveys before and after pregnancy showed no evidence of bone disease. Increasing anaemia caused concern for maternal and fetal welfare, ${ }^{18}$ and $600 \mathrm{ml}$ of red cells were given when the haemoglobin concentration reached 5.6 g/dl. Further transfusion shortly before delivery was essential for safe obstetrical management. 19

Hypertension early in pregnancy is associated with a poor prognosis, ${ }^{20}{ }^{21}$ and the factors responsible for its development are obscure and probably multiple, ${ }^{22}$ though it can be controlled by ultrafiltration. ${ }^{11}$ Our patient's blood pressure was well controlled until about 28 weeks; then diminishing hydramnios made estimation of her desirable weight uncertain and she became hypertensive between dialysis. Attempts at control by ultrafiltration were limited by hypotension during dialysis, and the large gravid uterus may have contributed to this by diminishing venous return. Extra dialysis was eventually needed to control circulatory overload but did not prevent the severe rise in blood pressure three days before delivery, which may have been due to increased intravascular volume caused by blood transfusion. Blood pressure was rapidly controlled with intravenous hydrallazine and maintained by dialysis. Though the premature contractions at 31 weeks were initially suppressed they recurred in subsequent dialyses, and finally labour could not be prevented. Attempts to increase ultrafiltration seemed to stimulate contractions and may have contributed to the onset of premature labour, but other factors known to be associated with premature labour-anaemia, ${ }^{18}$ hydramnios, and hypertension ${ }^{23}$ - were present. Dialysis and premature uterine contractions are associated, ${ }^{8}{ }^{1325}$ so we tried to keep volume changes to a minimum.

Severe anaemia, uraemia, and frequent dialysis are potential causes of impaired fetal growth. The apparently normal increase in biparietal diameter as assessed ultrasonically suggested that the fetal environment in our patient was satisfactory. As the time of conception was uncertain, however, so was the starting point of the assessment curve and the fetus might have been a small-for-dates baby throughout pregnancy following a growth curve shifted to the right. Paediatric neurological assessment suggested the baby's maturity was 32 weeks, and the birth weight of $1530 \mathrm{~g}$ was above the 25th percentile for infants of 32 weeks' gestation. ${ }^{25}$ Indeed, if allowance is made for maternal weight $(41 \mathrm{~kg})$ and height $(153 \mathrm{~cm})$ the birth weight was at the 50th percentile. ${ }^{26}$ Therefore we believe assessment of fetal maturity was correct and that fetal nutrition had been adequate.

A successful outcome may be achieved in patients receiving R.D.T., but not without significant hazard to mother and fetus and only with considerable family and hospital support. Close collaboration between obstetrician and nephrologist, supported by facilities for intensive neonatal care, are essential.

We thank sister B. Francis, sister I. Clifford, and the staff of the Hanbury dialysis unit, sister A. Nodder and the staff of the obstetric department, sister M. E. Bilby and the staff of the neonatal intensive care unit, and also the patient's husband, without whose care a successful outcome could not have been achieved. We also thank Dr. G. J. A. I. Snodgrass, consultant paediatrician, Mr. A. L. T. Easton, Consultant Obstetrician, and Miss P. Humpherson and Miss E. Todd for dietary advice and supervision.

\section{References}

${ }^{1}$ Board, J. A., et al., Obstetrics and Gynecology, 1967, 29, 318.

2 Rauramo, L., et al., Acta Obstetricia et Gynecologica Scandinavica, 1962 41, 357.

${ }^{3}$ Mackay, E. V., Australian and New Zealand fournal of Obstetrics and Gynaecology, 1963, 3, 21.

4 Tenney, B., and Dandrow, R. V., American fournal of Obstetrics and Gynecology, 1961, 81, 8.

5 Goodwin, N. J., et al., American fournal of Obstetrics and Gynecology, 1968,

$100,528$.
6 Confortini, P., et al., Proceedings of the European Dialysis and Transplant Association, 1971, 8, 74 .
Astini, P.,

7 Unzelman, R. F., Alderfer, G. R., and Chojnacki, R. E., Transactions of the American Society for Artificial Internal Organs, 1973, 19, 144

${ }^{8}$ Campbell, S., and Newman, G. B., Fournal of Obstetrics and Gynaecology of the British Commonwealth, 1971, 78, 513

- Dubowitz, L. M. S., Dubowitz, V., and Goldberg, C., fournal of Pediatrics 1970,77, 1 .

${ }^{0}$ Frankenberg, W. K., and Dodds, J. B., Fournal of Pediatrics, 1967, 71, 181.

11 Goldsmith, H. J., et al., Lancet, 1971, 2, 738.

12 Mitra, S., et al., American fournal of Medical Science, 1970, 259, 333.

13 Herwig, K. R., et al., American fournal of Obstetrics and Gynecology, 1965, 92, 1117.

14 Orme, B. M., et al., Transactions of the American Society for Artificial Internal Organs, 1968, 14, 402.

15 Beaudry, C., Carriere, S., and Barcelo, R., L'Union Medicine Canada, 1971, $100,100$.

${ }^{16}$ McDonald, H. N., and Good, W., fournal of Obstetrics and Gynaecology of the British Commonwealth, 1971, 78, 912 .

17 Department of Health and Social Security, Reports on Public Health and Medical Subjects, No. 120. London, H.M.S.O., 1969.

18 Ratten, G. J., and Beisher, N. A., Fournal of Obstetrics and Gynaecology of the British Commonwealth, 1972, 79, 228.

${ }^{9} \mathrm{McFee}, \mathrm{J}$. G., Clinical Obstetrics and Gynecology, 1973, 16, 153

20 Schewitz, L. J., (1971). Medical Clinics of North America, 1971, 55, 47 1 Felding, C. F., (1969). Acta Obstetricia et Gynecologica Scandinavica, 1969 Suppl. 2,1 .

22 Strauss, M. B., and Welt, L. G., Diseases of the Kidney, 2nd edn., p. 1165 Boston, Little, Brown and Company, 1971.

${ }^{23}$ Donald, I., Practical Obstetrical Problems, 4th edn., p. 742. London, Lloyd-Luke, 1969.

24 Pepperell, R. J., Adam, W. R., and Dawborn, J. K., Australian and New Zealand fournal of Obstetrics and Gynaecology, 1970, 10, 180.

25 Gruenwald, P., American Fournal of Obstetrics and Gynecology, 1966, 94, 1112.

26 Thomson, A. M., Billewicz, W. Z., and Hytten, F. E., Fournal of Obstetrics and Gynaecology of the British Commonwealth, 1968, 75, 903. 